\title{
Influences of the Textured Surface Micro-Texture Depth on the Friction Coefficient
}

\author{
Moussa Magara Traore1,2 \\ ${ }^{1}$ State Key Laboratory for Manufacturing Systems Engineering, School of Mechanical Engineering, Xi'an Jiaotong University, \\ Xi'an, China \\ ${ }^{2}$ Ecole Normale d'Enseignement Technique et Professionnel du Mali, Cité Universitaire de Kabala, Bamako, Mali \\ Email:mmtraore@enetp.edu.ml, mapatra@gmail.com
}

How to cite this paper: Traore, M.M. (2020) Influences of the Textured Surface Micro-Texture Depth on the Friction Coefficient. World Journal of Mechanics, 10, 221-228.

https://doi.org/10.4236/wjm.2020.1012016

Received: September 25, 2020

Accepted: December 14, 2020

Published: December 17, 2020

Copyright (c) 2020 by author(s) and Scientific Research Publishing Inc. This work is licensed under the Creative Commons Attribution International License (CC BY 4.0).

http://creativecommons.org/licenses/by/4.0/

\section{(cc) (i) Open Access}

\begin{abstract}
The use of textured surfaces in lubrication to improve the tribological characteristics has been widely studied. The understanding of the textured surface geometric parameters influences on these tribological characteristics could help to improve their applications in industry. In this paper, we purpose to analyze the influence of the micro-texture depth on the friction coefficient experimentally. The experiment is conducted using different copper alloy samples have been the first laser textured with different micro-hole depth $(40.83 \mu \mathrm{m}$ and $46.36 \mu \mathrm{m})$. A 3D electronic Olympus microscope is used to visualize the shapes of the holes and find the depths. Then, the friction test has been conducted using these samples with the same velocity. The time variation of the friction coefficient is plotted and analyzed. The analysis of time variation of the friction coefficient shows a reduction of friction coefficient with the increase of the micro-hole depth has been observed. In some cases, this reduction is significant.
\end{abstract}

\section{Keywords}

Friction Coefficient, Tribology, Textured Surfaces

\section{Introduction}

The textured surfaces are used in hydrodynamic lubrication in machinery design. To make micro-holes on the surfaces in contact may improve the tribological properties. The lubricant can then be provided at the surface contact by the small reservoirs, reducing the friction and increase the lifetime of the contacts.

Several researches were related to different aspects of textured surfaces in lubrication. Some of them were done using different methods to do the surface 
texture and then analyze the tribological properties. A well-defined surface texture was produced by lithography and anisotropic etching of silicon wafers [1]. A nanostructure superhydrophobic surface that minimizes the liquid-solid contact area so that the liquid flows predominantly over a layer of air had been engineered [2], the surface has demonstrated dramatic slip effects: a slip length of $\sim 20 \mathrm{~mm}$ for water flow had been also found. Predictions of the friction coefficient and the wear depth, which were obtained from a Global Incremental Wear Model "GIWM", are in good agreement with experiments and successfully validate the transferability of the model [3]. A numerical simulation was done with different fluid speeds to determine the flow characteristics (shear stress, pressure) on different faces of micro-asperities [4]; a theoretical method was also used to find the approximated micro-asperities dimensions [5].

The effects of hydrophobic surfaces on skin-friction drag have been investigated through direct numerical simulations of turbulent channel flow [6]. A numerical study of different shapes shows the effects of deterministic asperities on hydrodynamic lubrication [7]. The slip effects of water effects in hydrophilic and hydrophobic microchannels have been experimentally examined [8]. The studies cited above have not analyzed the micro-asperities depth effects on the hydrodynamic characteristics.

In this study, we purpose to analyze the influence of the micro-texture depth on the friction coefficient experimentally

Thus, a cylindrical copper alloy ZQSn6.5 - 0.1 is used as experimental samples, the circular surface is laser textured with different depth of micro-hole for each sample. These samples with different micro-holes depth were used to do an experimental analysis of the influence of the micro-hole's depth on the time variation of friction coefficient. The results show the reduction of the friction coefficient.

\section{Samples Preparation}

Several operations have been done on a Laser Marking system. The goal of these operations was to realize the texture represented in Figure 1. The texture should be realized with successive laser spots, to obtain different depths of produced micro holes.

The sample discs were prepared from copper alloy ZQSn6.5 - 0.1, by machining, hardening $(850 \mathrm{HV})$ and polishing to mirror smoothness $(\mathrm{Ra}=0.05 \mu \mathrm{m})$. The disc diameter size is $45 \mathrm{~mm}(\varnothing 45 \mathrm{~mm})$. Discs were textured with three different patterns of micro-holes, different in terms of depth and analogous diameter and density. For this Nd: YAG laser with an average power of $25 \mathrm{~A}$, a wavelength of $1064 \mathrm{~nm}$ and frequency of $15 \mathrm{kHz}$ was used. The pulse duration, full-width at half-maximum (FWHM), was of the order of ns. After laser texturing, the discs were polished again to remove the bumps on the extremity of the micro holes and chemically treated using the ferric chloride $(0.2 \mathrm{~g} / \mathrm{ml})$ and the hydrochloric acid $(0.1 \mathrm{~mol} / \mathrm{l})$ to clean up. Figure 2(a) and Figure $2(\mathrm{~b})$ show the difference between the samples before and after treatment. 


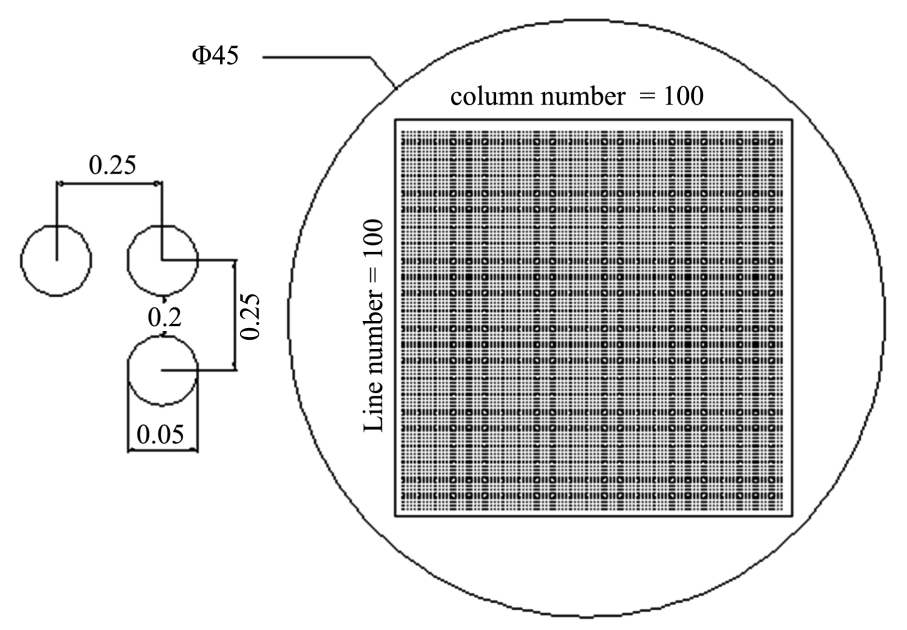

Figure 1. CAD draws of sample.

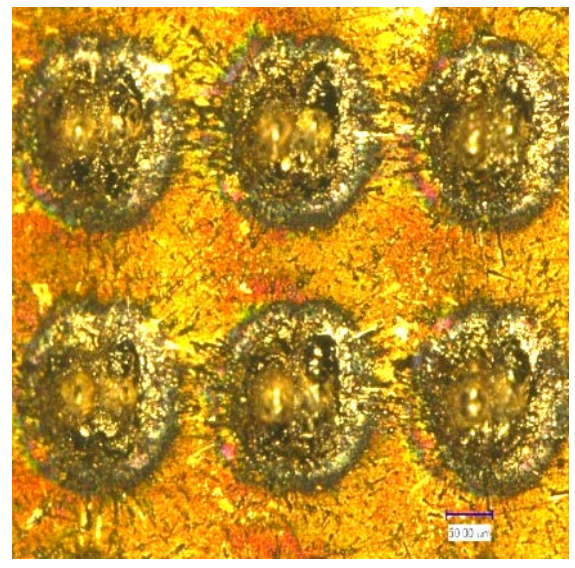

(a)

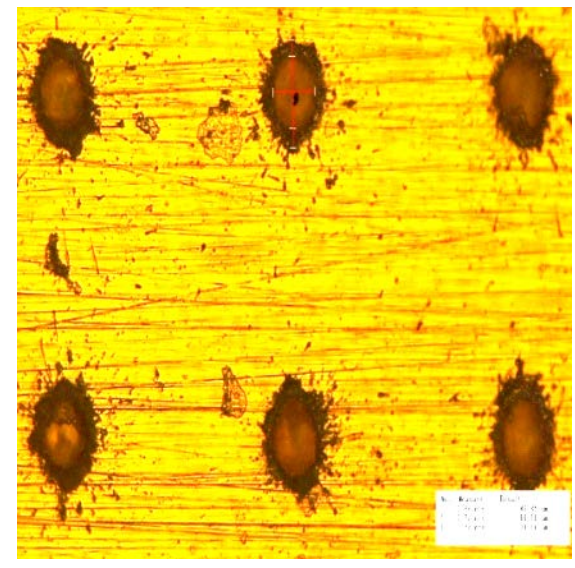

(b)

Figure 2. (a) Sample surface before treatment; (b) Sample surface after treatment.

Figures 3(a)-(c) show the three intermediate measured shapes of the ablated area after 5, 10 and 15 consecutive laser pulses on the same spot, resulting in micro holes with depth of $36.2 \mu \mathrm{m}, 40.83 \mu \mathrm{m}$ and $46.36 \mu \mathrm{m}$, respectively. From such scan profiles, average crater depth and crater diameters were measured. For that operation a 3D electronic Olympus microscope is used to visualize the holes shapes and find the depths.

\section{Friction Experiment}

Friction tests were carried out using a pin-on-disc friction machine. The pin was a flat-ended $25-$ and $50-\mathrm{mm}$ diameter hardened $100 \mathrm{Cr} 6$ steel roller. In order to have a flat contact between the pin and the textured samples, the pin was first run against $\mathrm{SiC}$ abrasive papers with 1000 and 2000 grit. Load and rotation speed were set to $20 \mathrm{~N}$ and $250 \mathrm{rpm}$, respectively, with the pin-disc machine acting as a grinding/polishing machine. The friction test machine and sample are shown respectively in Figure 4 and Figure 5. Schematic diagram of contact configuration is shown in Figure 6. 


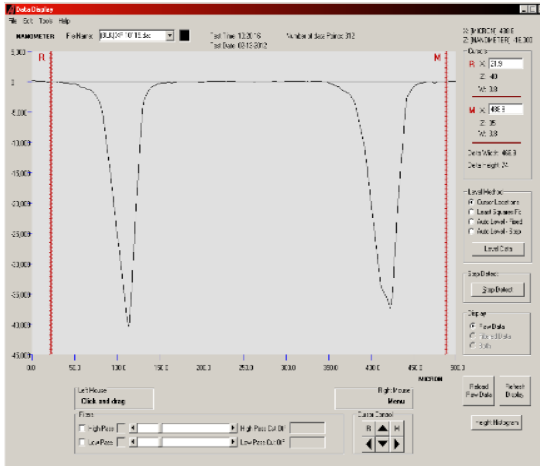

(a)

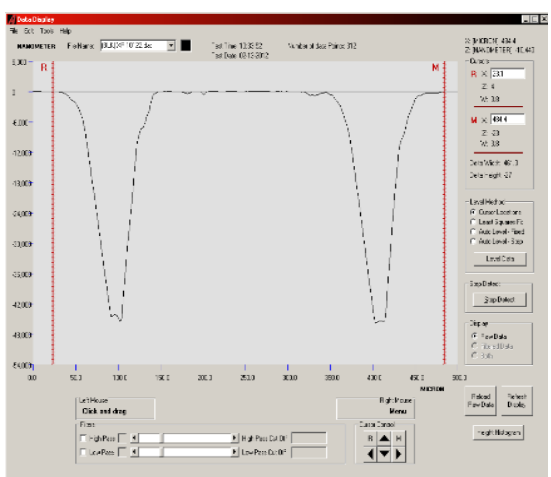

(b)

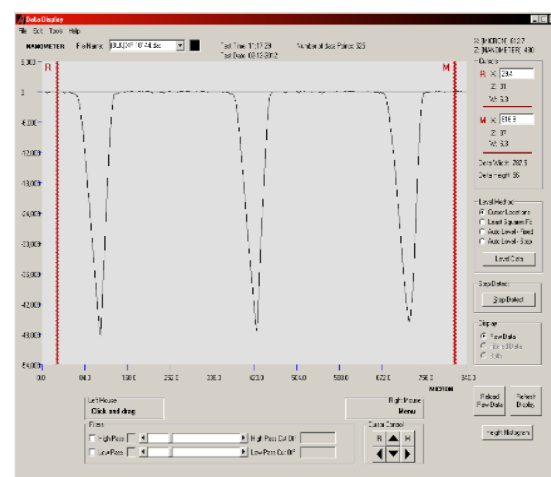

(c)

Figure 3. (a) Micro holes with $36.2 \mu \mathrm{m}$ as depth; (b) Micro holes with $40.83 \mu \mathrm{m}$ as depth; (c) Micro holes with $46.36 \mu \mathrm{m}$ as depth.

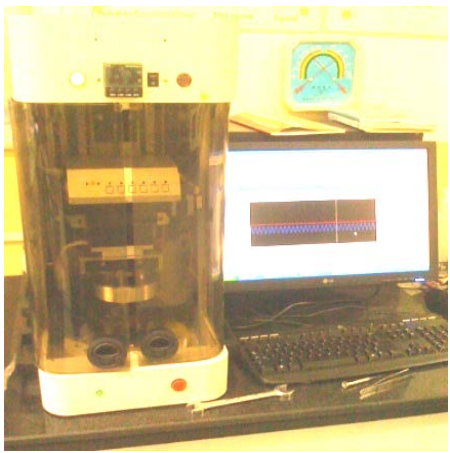

Figure 4. Pin on disc friction test machine.

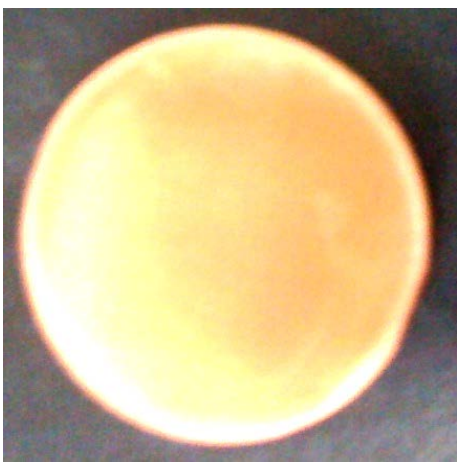

Figure 5. Copper alloy textured sample. 


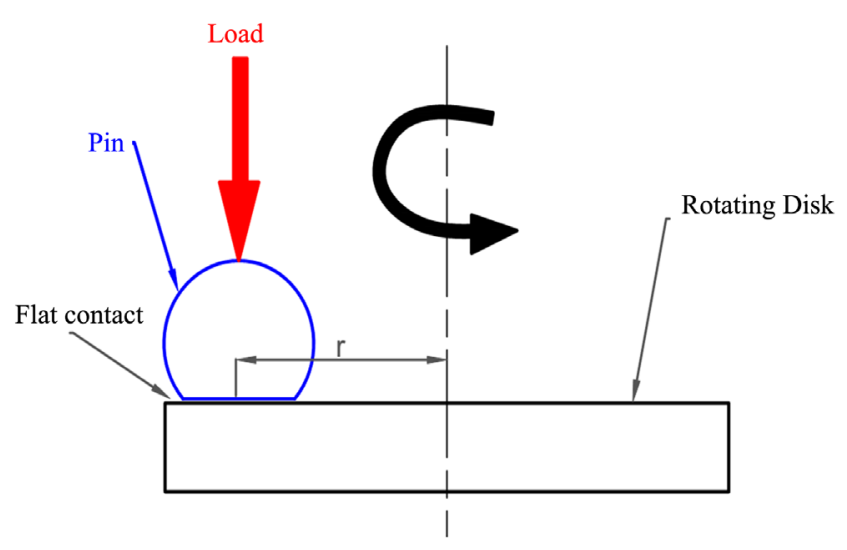

Figure 6. Schematic diagram of contact configuration.

\section{Results}

The friction tester produces a series of data in the form of a text document which is then introduced into the Originlab software to plot the variation of the coefficient of friction with time.

The results are presented on the different Figures 7-10 respectively for radius $\mathrm{R} 1, \mathrm{R} 2, \mathrm{R} 3$ and R4 where R1 $=4.9998 \mathrm{~mm}, \mathrm{R} 2=5.9998 \mathrm{~mm}, \mathrm{R} 3=7.9995 \mathrm{~mm}$ and $\mathrm{R} 4=9.9998 \mathrm{~mm}$. Each figure shows the graph of the friction coefficient variation for two different depths of micro hole: $10 \mathrm{t}=40.83 \mu \mathrm{m}$ and $15 \mathrm{t}=46.36$ $\mu \mathrm{m}$, respectively represented in red and black. These graphs are plotted from experiment data using originlab software.

\section{Discussions}

Figure 7 represent the results for the radius $\mathrm{R} 1=4.9998 \mathrm{~mm}$. the variation of the friction coefficient is plotted for different micro hole depth (10 times $=40.83$ $\mu \mathrm{m}$ and 15 times $=46.36 \mu \mathrm{m})$. here the decrease of the coefficient of friction is noted in accordance to the increase of the micro hole depth. The graph of the deeper micro-hole (in black) gives lower values of friction coefficient.

In Figure 8, the radius R2 $=5.9998 \mathrm{~mm}$. The variation of the friction coefficient is plotted for different micro hole depth $(10$ times $=40.83 \mu \mathrm{m}$ and 15 times $=46.36 \mu \mathrm{m})$. Here also the decrease of the coefficient of friction is noted in accordance to the increase of the micro-hole depth. Here also the graph of the deeper micro-hole (in black) gives lower values of friction coefficient.

In Figure 9, the radius R3 $=7.9995 \mathrm{~mm}$. The variation of the friction coefficient is plotted for different micro hole depth $(10$ times $=40.83 \mu \mathrm{m}$ and 15 times $=46.36 \mu \mathrm{m})$. Here also the decrease of the coefficient of friction is noted in accordance to the increase of the micro-hole depth significantly. Here also the graph of the deeper micro-hole (in black) gives lower values of friction coefficient.

In Figure 10, the radius $\mathrm{R} 4=9.9998 \mathrm{~mm}$. The variation of the friction coefficient is plotted for different micro hole depth (10 times $=40.83 \mu \mathrm{m}$ and 15 times $=46.36 \mu \mathrm{m})$. Here also the decrease of the coefficient of friction is noted in 


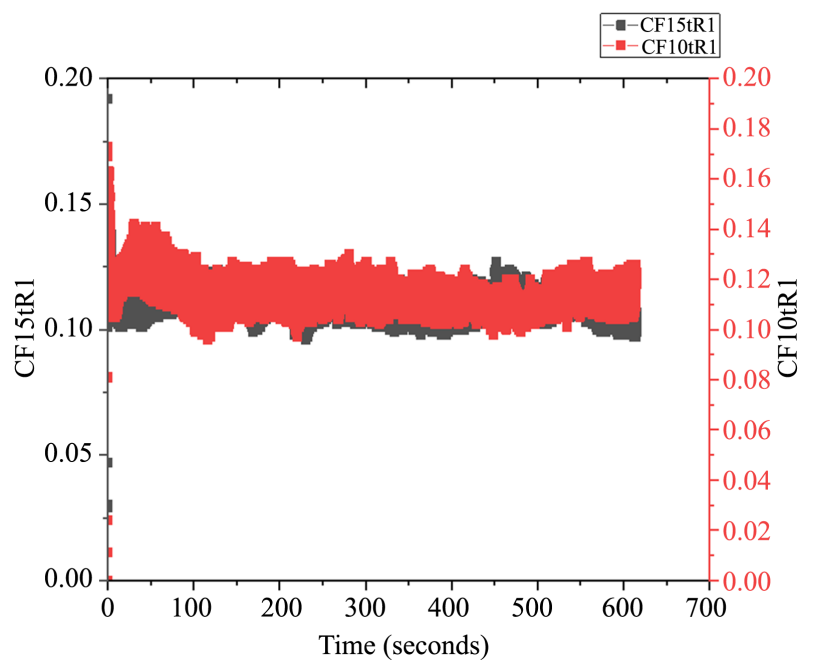

Figure 7. Friction coefficient variation for R1 $=4.9998 \mathrm{~mm}$.

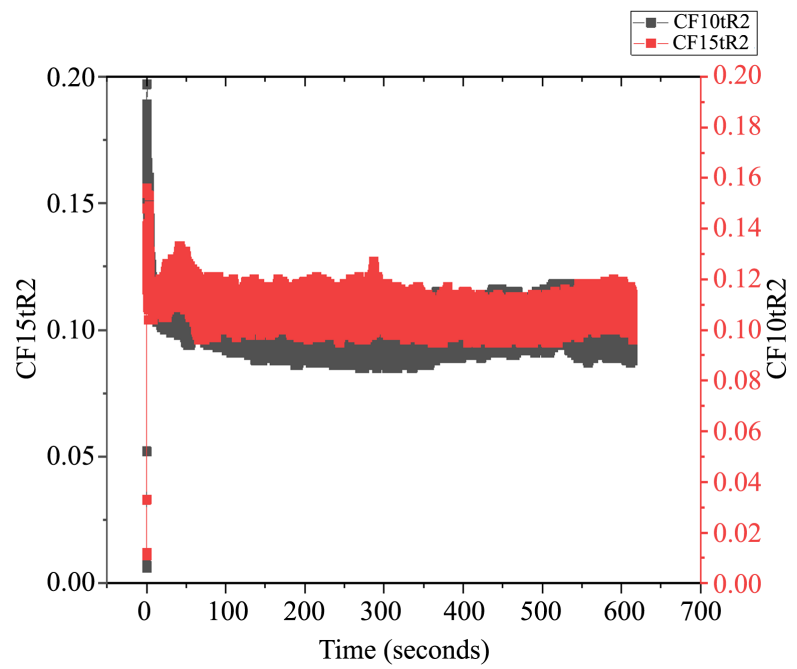

Figure 8. Friction coefficient variation for R2 $=5.9998 \mathrm{~mm}$.

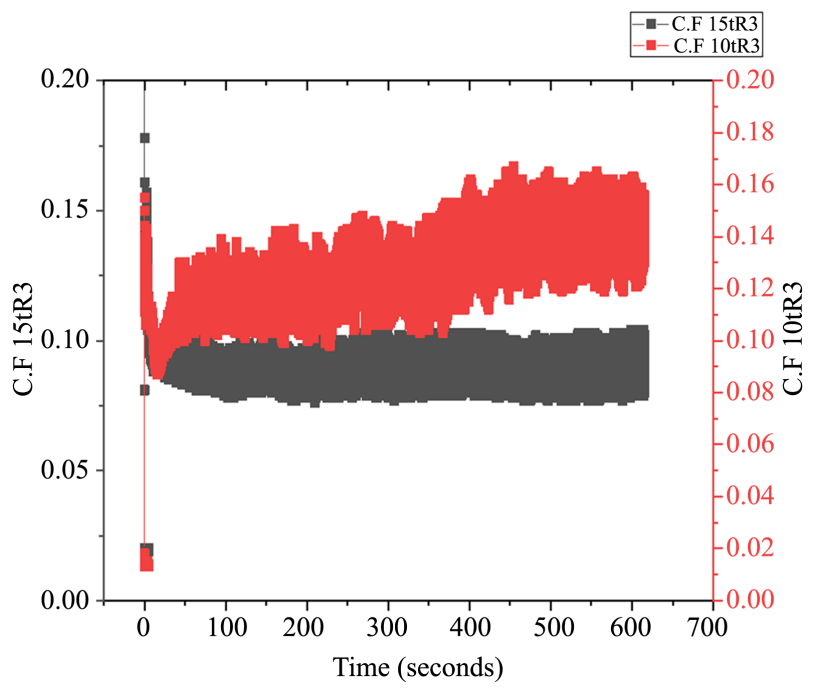

Figure 9. Friction coefficient variation for R3 $=7.9995 \mathrm{~mm}$. 


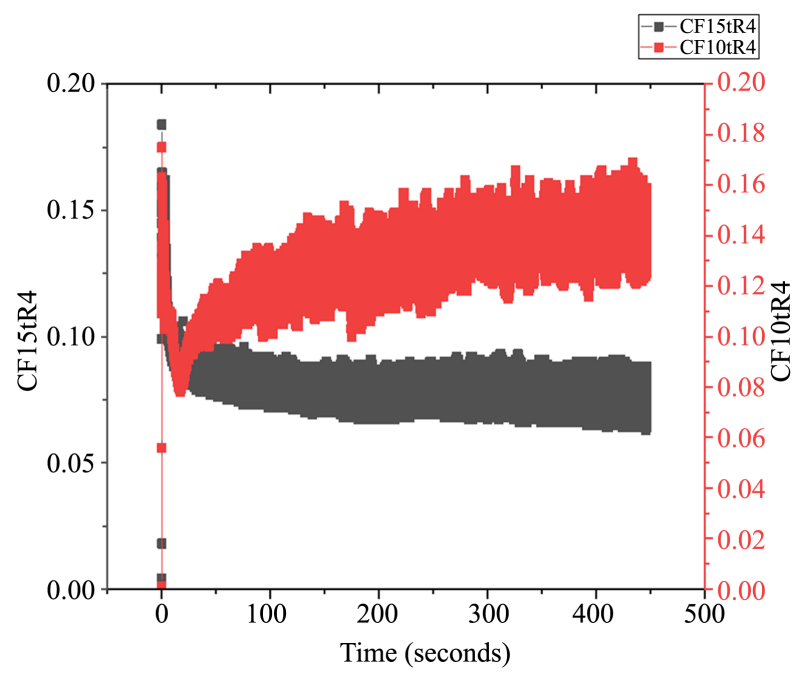

Figure 10. Friction coefficient variation for R4 $=9.9998 \mathrm{~mm}$.

accordance to the increase of the micro hole depth very significantly. In this case, the large decrease is due to the fact that with this radius, the contact is made with many more micro holes on the surface of the sample.

For these three cases, for same radius and same velocity, the friction coefficient decreases when the depth increase.

\section{Conclusions}

In this study, a laser surface texturing (LST) is used to fabricate micro-dimples with different depths was fabricated and the friction test was realized to show the influences of these micro-dimples' depth variation on the tribological parameters.

This study allowed us to understand the influences of the micro-dimples' depth on the friction coefficient. The obtained results from this experiment confirm the obtained results from the numerical simulation [9]. The results are also confirmed in some other experimental studies [10].

Thus, a significant reduction of friction coefficient with the increase of the depth value was observed.

\section{Conflicts of Interest}

The author declares no conflicts of interest regarding the publication of this paper.

\section{References}

[1] Pettersson, U. and Jacobson, S. (2003) Influence of Surface Texture on Boundary Lubricated Sliding Contacts. Tribology International, 36, 857-864. https://doi.org/10.1016/S0301-679X(03)00104-X

[2] Choi, C.H. and Kim, C.J. (2006) Large Slip of Aqueous Liquid Flow over a Nanoengineered Superhydrophobic Surface. Physical Review Letters, 96, Article No. 066001. https://doi.org/10.1103/PhysRevLett.96.066001 
[3] Steiner, L., Bouvier, V., May, U. and Huber, N. (2010) Simulation of Friction and Wear in DLC/Steel Contacts for Different Loading Histories and Geometries: Ballon-Plate Configuration and Piston-Cylinder-Contacts. Tribology International, 43, 1410-1416. https://doi.org/10.1016/j.triboint.2010.01.012

[4] Traore, M.M. and Wang, L. (2011) The Wear and Drag Predictions of the 2D Micro-Asperities on Textured Wall. Advanced Materials Research, 284-286, 1489 1492. https://doi.org/10.4028/www.scientific.net/AMR.284-286.1489

[5] Traore, M.M. and Wang, L. (2011) The Wear and Drag Predictions of the Micro-Asperities on Textured Wall. Advanced Materials Research, 314-317, 1886-1890. https://doi.org/10.4028/www.scientific.net/AMR.317-319.1886

[6] Min, T. and Kim, J. (2004) Effects of Hydrophobic Surface on Skin-Friction Drag. Physics Fluids, 16, Article ID: L55. https://doi.org/10.1063/1.1755723

[7] Nacer, T.I., Fillon, M. and Maspeyrot, P. (2011) Effect of Textured Area on the Performances of a Hydrodynamic Journal Bearing. Tribology International, 44, 211 219. https://doi.org/10.1016/j.triboint.2010.10.003

[8] Choi, C.H., Johan, K., Westinv, A. and Breuer, K.S. (2003) Apparent Slip Flows in Hydrophophilic and Hydrophobic Channels. Physics Fluids, 15, 2897.

https://doi.org/10.1063/1.1605425

[9] Traore, M.M. and Wang, Li. (2013) Influences of the Flow Speed and the Micro-Texture Deepness on the Hydrodynamic Lubrication Characteristics. Journal of Computational and Theoretical Nanoscience, 10, 419-422. https://doi.org/10.1166/jctn.2013.2714

[10] Vilhena, L.M., Podgornik, B., Vižintin, J. and Možina, J. (2011) Influence of Texturing Parameters and Contact Conditions on Tribological Behaviour of Laser Textured Surfaces. Meccanica, 46, 567-575. https://doi.org/10.1007/s11012-010-9316-x 